\title{
Experimental study on control of Limnoperna fortunei biofouling in water transfer tunnels
}

\author{
Mengzhen Xu ${ }^{a}$, Gustavo Darrigran ${ }^{\mathrm{b}}$, Zhaoyin Wang ${ }^{\mathrm{a}, *}, \mathrm{Na}$ Zhao ${ }^{\mathrm{a}}$, Cheng Chieh Lin ${ }^{\mathrm{c}}$, \\ Baozhu Pan ${ }^{\mathrm{d}}$ \\ ${ }^{a}$ State Key Laboratory of Hydroscience and Engineering, Tsinghua University, P.O. Box 10008, Beijing, China \\ ${ }^{\mathrm{b}}$ CONICET, División Zoología Invertebrados, Museo de La Plata, Paseo del Bosque s/n, 1900 La Plata, Argentina \\ ${ }^{\mathrm{c}}$ Program in Civil and Hydraulic Engineering, Feng Chia University, Taiwan, China \\ ${ }^{\mathrm{d}}$ Changjiang River Scientific Research Institute, Wuhan 430010, China
}

Available online 17 December 2014

\begin{abstract}
The golden mussel (Limnoperna fortunei) is a filter-collector macroinvertebrate species originating from southern China. It easily invades water transfer tunnels and attaches onto tunnel walls and structures with extremely high density, resulting in biofouling, pipe clogging, structure corrosion, a decrease in water transfer efficiency, and water pollution. It has become a prevalent problem and has caused concern all over the world. However, an effective and environment friendly method of controlling golden mussel invasion has not yet been approved. This study is aimed to propose measures for preventing golden mussel invasion and biofouling in the water transfer tunnels of the East River Water Source Project (ERWSP), which transfers water from the East River to Shenzhen, southern China for 10 million people. Long-term samplings and observations of the East River water were performed to study the golden mussel's invading pattern. Flume experiments were done to study the golden mussel's attachment on 14 different materials and performance in turbulent flows. An integrated ecological prevention pool was designed and constructed based on the flume experimental results for preventing the golden mussel invasion in the scale model tunnels of the ERWSP. The major technology of the ecological pool was preventing the golden mussel from entering the tunnels by attracting veligers to attach on geotextile cloth, attracting mussels to attach on bamboo, and killing veligers with high-frequency turbulence. An eight-month application experiment showed that the ecological pool successfully controlled the golden mussel invasion and biofouling in the scale model tunnels. The mussel density on the attachment materials decreased sharply as the distance of the materials from the pool entrance increased; the turbulence was effective in killing veligers that escaped from the attachment materials. No mussel was found on the model tunnels. Thus, the integrated ecological prevention pool is recommended as a successful measure for controlling the golden mussel invasion and biofouling in water transfer tunnels. (C) 2014 International Association for Hydro-environment Engineering and Research, Asia Pacific Division. Published by Elsevier B.V. All rights reserved.
\end{abstract}

Keywords: Water transfer tunnels; Golden mussel invasion; Biofouling; Attachment attracting; Ecological prevention

\section{Introduction}

Limnoperna fortunei (Dunker, 1856) or the golden mussel, is a freshwater invading bivalve belonging in the family Mytilidae. It is a filter-collector macroinvertebrate species

\footnotetext{
* Corresponding author. Tel.: +86 1062773448.

E-mail addresses: xumz07@gmail.com, mzxu@tsinghua.edu.cn (M. Xu), zywang@tsinghua.edu.cn (Z. Wang).
}

originating from southern China. This species colonizes widespread habitats with water temperature among $0-35^{\circ} \mathrm{C}$, flow velocity among $0.1-2 \mathrm{~m} / \mathrm{s}$, water depth among $0.1-40 \mathrm{~m}$, dissolved oxygen among $0.2-11.3 \mathrm{mg} / \mathrm{L}, \mathrm{pH}$ among 6.0-7.8, and Calcium concentration to $3.96 \mathrm{mg} / \mathrm{L}$ (Morton, 1982; Márcia, 2006; Darrigran et al., 2011, 2012). The golden mussel shows characteristics similar to those of the marine members of the family, i.e. an epibyssate habit and a planktonic larvae measuring only a few microns (Darrigran et al., 2007). It should be noted that until now, the golden 
mussel planktonic larvae have never been found in the waters of China. In China, it is revealed that the golden mussel becomes sexually mature when its shell length reaches $6-8 \mathrm{~mm}$ (Group of Pipeline Study (1973)). However, in a temperate climate of Argentina, the golden mussel is found sexually mature at the shell length of $5 \mathrm{~mm}$ (Darrigran et al., 1999).

Inter-basin water transfer projects have been widely used to solve uneven distribution of water resources and water shortages in China. Along with diversion of water resources, the golden mussel has also been inadvertently transferred to new aquatic environments, resulting in a quick and uncontrolled spread of the species. For instance, the water transferred from East River to Hong Kong introduced the golden mussel into the aquatic ecosystem of Hong Kong and has disrupted the native aquatic community (Morton, 1977). In the water cooling system of the Wuhan Iron and Steel Company in Hubei, central China the golden mussel clogged the water-supply pipes and caused great economic loss (Group of Pipeline Study (1973)). In the past, the golden mussel was found only in southern China with the Yangtze River as its north boundary (Liu et al., 1979). However, the species was found in the Yellow River basin in the 1980s, and recently it has been found in the waters in Beijing (Ye et al., 2011).

The golden mussel has also invaded the aquatic ecosystems and hydraulic structures in South America and other Asian countries (Darrigran, 2002; Boltovskoy et al., 2006). It is a very effective ecosystem engineer, altering both ecosystem structure and function, and causes great ecological and economic impacts (Darrigran and Damborenea, 2011). The clogging of cooling water pipes caused by dead mussels stopped raw water pumping to a water purification plant and caused the shutdown of a turbine dynamo-electric generator in a hydraulic power plant in Japan (Magara et al., 2001). At the beginning of 1994, Limnoperna fortunei caused the first known case of freshwater industrial macrofouling in South America (Darrigran, 2010). This event occurred at the intake for the drinking water plant of the city of La Plata, Argentine. Since, Limnoperna fortunei infests all types of man-made facilities: treatment plants, irrigation channels, reservoirs, fisheries and several most important nuclear, hydroelectric and thermal power plants of the Plata Basin (Darrigran et al., 2007; Darrigran, 2010; Pereyra et al., 2012) and the golden mussel has also created significant problems for the city of Córdoba, one of the most important tourist city of Argentina. This city has a population of $1,400,000$, which has one of the highest living standards in the country. In February 2008, the golden mussel shells accumulate in the cooling system from downtown San Roque, causing the plant to disconnect. This loss of power in turn closes distribution facilities and water treatment throughout the city, leaving the city of Cordoba, in the summer, no water for $24 \mathrm{~h}$ (Darrigran, 2010).

The golden mussel invasion and biofouling in water transfer systems has drawn attention because it has resulted in a high resistance to water flow in tunnels, corrosion of pipe walls and even clogging of tunnels. Additionally, the invasion has caused water pollution and ecological imbalance in the regions that receive water infested with the golden mussel (Darrigran, 2002). Therefore, quite a few researches have been done to study the golden mussel's biological and ecological features. It is found that it shares several biological and ecological features with the North American invasive pest zebra mussel (Dreissena polymorpha), like size, growth speed, and colonization on hard substrata by means of strong byssuses (Morton, 1979; Ricciardi, 1998; Karatayev et al., 2007). Both species are invasive by nature and endowed with a strong byssus for attaching onto their habitats, allowing them to easily invade natural and artificial aquatic systems, resulting in high-density attachment that causes serious biofouling. Invasion of the golden mussel in a new habitat results in changes in the feeding habits of fish and, consequently, the composition of the macroinvertebrate community (Darrigran and Ezcurra, 2000; Darrigran and Damborenea, 2005; Penchaszadeh et al., 2000).

Finding strategies to reduce biofouling caused by the golden mussel invasion has been studied for decades all over the world. Various chemical and physical measures of getting rid of the golden mussel's attachment, such as coating pipe walls (Luo, 2006), poisoning with pesticide (Darrigran and Damborenea, 2006; Pereyra et al., 2011, 2012), spraying with hot water (Morton, 1982), trapping with filters (Darrigran, 2002), using ultraviolet irradiation, washing with high velocity flow, removing artificially with scrapers (Xu et al., 2009) have been employed. However, such measures can themselves contribute to water pollution, damage water transfer tunnels, or cost too much to be of practical use. Preventing the golden mussel's invasion into water transfer tunnels is the most effective strategy to mitigate biofouling (Simberloff, 2001). Therefore, it is essential to understand the ways of dispersion (Belz et al., 2012) and invasion of the golden mussel. Ecological methods of preventing the golden mussel invasion in water transfer tunnels were applied in the East River Water Source Project (ERWSP) in this study.

\section{Study area and methods}

\subsection{East River Water Source Project}

As shown in Fig. 1, the East River Water Source Project (ERWSP) transfers water from the East River and its tributary Xizhijiang River to Shenzhen, southern China for 10 million people's use. The ERWSP consists of $17 \mathrm{~km}$ long double steel pipes (2.6 $\mathrm{m}$ in diameter), an $80 \mathrm{~km}$ long concrete tunnel (3.2 $\mathrm{m}$ in width and $4.0 \mathrm{~m}$ in height), several sections of culverts, and numerous valves. The tunnel entrance is located at the intake of the Dongjiang Pump Station (East River intake). The intake of the Xizhijiang Pump Station (Xizhijiang River intake) is located $17 \mathrm{~km}$ downstream from the tunnel entrance. This project has suffered from the golden mussel biofouling since it started operation in 2001. Attachment density of the mussels is 10,000 ind $/ \mathrm{m}^{2}$ on average and as 


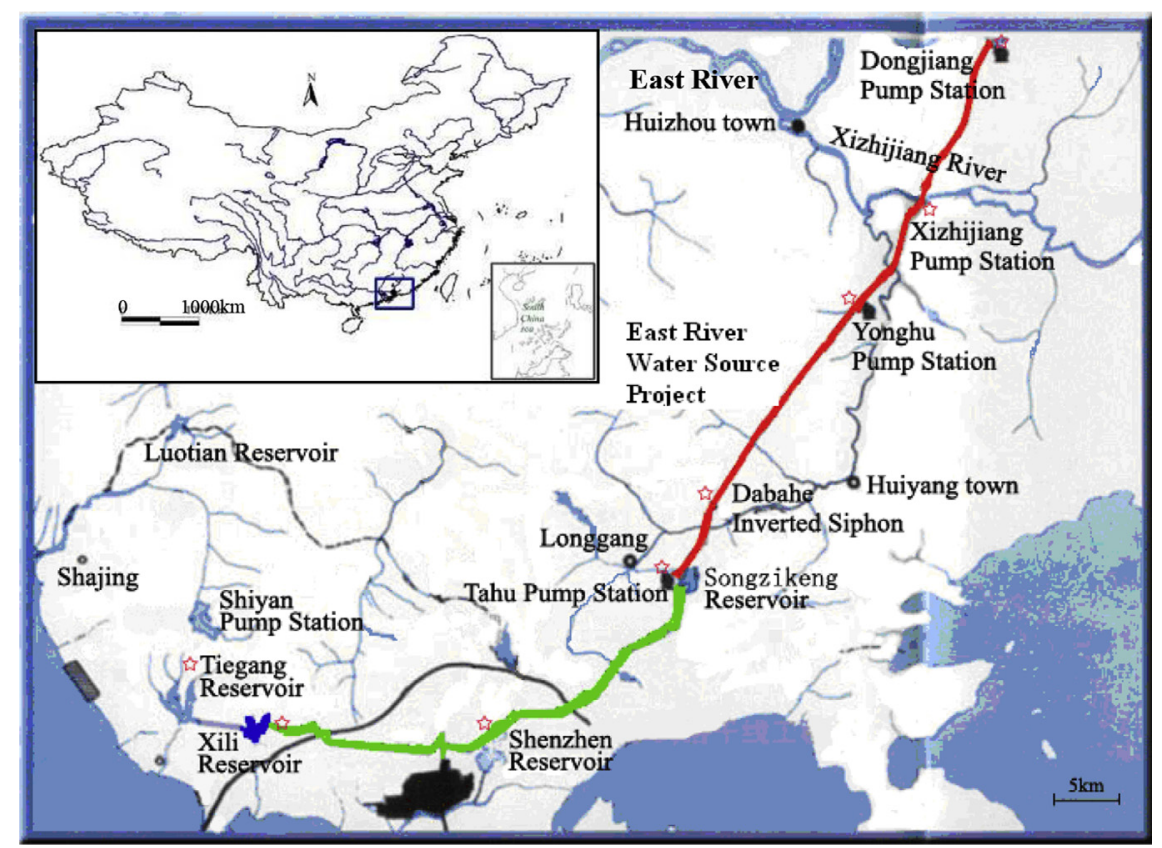

Fig. 1. Layout of the tunnels of East River Water Source Project: red line - water transfer tunnels, green line - water deliver tunnels. (For interpretation of the references to colour in this figure legend, the reader is referred to the web version of this article.)

high as 50,000 ind. $/ \mathrm{m}^{2}$ on some sections. Thickness of the golden mussel clusters exceeds $10 \mathrm{~cm}$ on pipe walls, valves, gates, and other structures, resulting in concrete wall corrosion and high resistance for water transferring (Fig. 2a). Additionally, fungi species growing on dead mussels results in water pollution (Fig. 2b). Artificial clearance of the mussels has being conducted year after year. However, the biofouling became more and more severe after each clearance.

\subsection{Study method}

Long-term samplings and observations of water samples taken from the East River and its tributary Xizhijiang River were conducted to study the golden mussel's invasion way and performance in water flow. Flume experiments were performed to study the attachment characteristics. Furthermore, an integrated ecological prevention pool was designed and constructed based on the results of long-term observations and flume experiments to study prevention methods of the golden mussel invasion in the scale model tunnels of the ERWSP.

\subsubsection{Long-term samplings and observations}

In the 1970s, it was estimated that the golden mussel veliger larvae develop inside the parental mussels and then enter into water when the veligers have byssuses for attaching onto materials; therefore, their invasion is limited to a short distance due to their poor crawl ability (Group of Pipeline Study (1973)). However, according to an investigation of the $120 \mathrm{~km}$ long tunnels of the ERWSP, it was found that the whole tunnel system suffered from the golden mussel biofouling, which means that the invasion ability of the species is far higher than its own crawl ability (Ye et al., 2011). It is explained that the golden mussel larvae experience a planktonic veliger stage, which can invade with water flow over long distances. With the aim of finding larvae, water samples were taken from the East and Xizhijiang rivers every week (a)

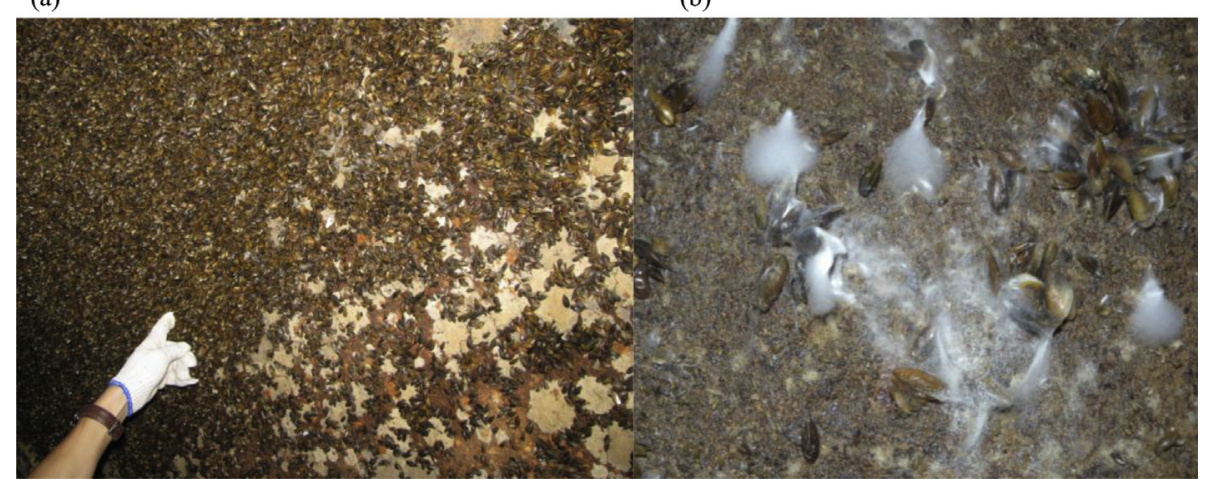

Fig. 2. (a) The golden mussel biofouling on water transfer tunnels; (b) Fungi developed on dead mussels. 
from January 2010 to December 2012 to detect the plankton veligers. A water pumping system was designed and used for taking water samples from different water depths. For each sample, $400 \mathrm{~L}$ of water was taken and filtered through plankton net with mesh of $64 \mu \mathrm{m}$. The concentrated sample was observed under a microscope-camera system (SmartV Camera \& MIVNT Image Analysis Software, Yongheng Shanghai). All of plankton veligers were photographed and documented with number, size, living status, and densities of veligers were calculated. Furthermore, living veligers were treated with high frequency turbulent flow $(>30 \mathrm{~Hz})$, which was generated by water flow passed through plates embedded with holes (diameter of holes: $10 \mathrm{~mm}$, interval between holes: $2 \mathrm{~mm}$, see details of the turbulent flow system in Xu (2012)).

\subsubsection{Experiments of the golden mussel's attachment}

Preliminary experiments were conducted to observe the golden mussel's attachment on 14 different materials: bamboo, plastic plane with lumpy surfaces, smooth PP plane (PP plane: plastic plane, as the same in the following text), rough PP plane, PP plane with cement mortar, geotextile cloth (four different types), woven net, smooth glass, hemp rope, ceramic tile, concrete slab, and it was found that the attachment densities were similar on the different types of geotextile cloth, but very different on the other nine materials (Xu et al., 2012). According to the preliminary experimental result, representative materials: bamboo, plastic plane with lumpy surfaces, PP plane (one rough surface and one cement mortar surface), geotextile cloth, and woven net were chosen and set in a flume for a long-term attachment experiment.

Fig. 3a shows the layout of the experimental flume, which consisted of a fore bay (I) and four sections (II-V) of open channels with different widths and different bed slopes to obtain different flow velocities. Water was pumped from the Xizhijiang River to the flume, flowing from Section I to
Section $\mathrm{V}$ then drained out from the flume. Four frames fixed with the representative materials, as shown in Fig. 3b, were set in the Sections II-V. Flow velocities of these sections were kept between 0.3 and $0.6 \mathrm{~m} / \mathrm{s}$, which is suitable for the golden mussel's attachment (Xu, 2012). The attachment densities were measured by counting the numbers of the attached mussels on the known surfaces of the different materials for different attachment periods: one day, one week, two weeks, and four weeks after the start of the experiment, respectively. The attachment force of the stably attached mussels on the different materials was measured using a Digital Push \& Pull Tester (0.01-50 N, SH-50, Wenzhou). High-velocity flows were used to flush the attached mussels to test the attachment force of the golden mussel.

\subsubsection{Long-term experiment of integrated ecological prevention}

Based on the results of the long-term observations and attachment experiments, an ecological prevention strategy was proposed that combined two techniques: attracting the mussels to attach onto their favourite materials and killing the veligers with high frequency turbulent flow. An integrated ecological prevention pool was designed and constructed for the experimental study of preventing the golden mussel invasion in the scale model tunnels of the ERWSP. Fig. 4 shows the layout and materials of the experimental system, which included the prevention pool and the scale model tunnels. The experiment was performed from March to October 2011, covering the reproduction peaks of the golden mussel in south China (Xu, 2013).

During the experiment, water was pumped from the Xizhijiang River to the fore bay (Pump discharge: $240 \mathrm{~m}^{3} / \mathrm{h}$ ), then flowed through to the prevention pool (total length: $34 \mathrm{~m}$, width: $2.2 \mathrm{~m}$, height: $1.6 \mathrm{~m}$ ), which consisted of three attachment sections: horizontal bamboo rafts (8 $\mathrm{m}$ long), vertical bamboo rafts ( $8 \mathrm{~m}$ long), vertical geotextile cloth

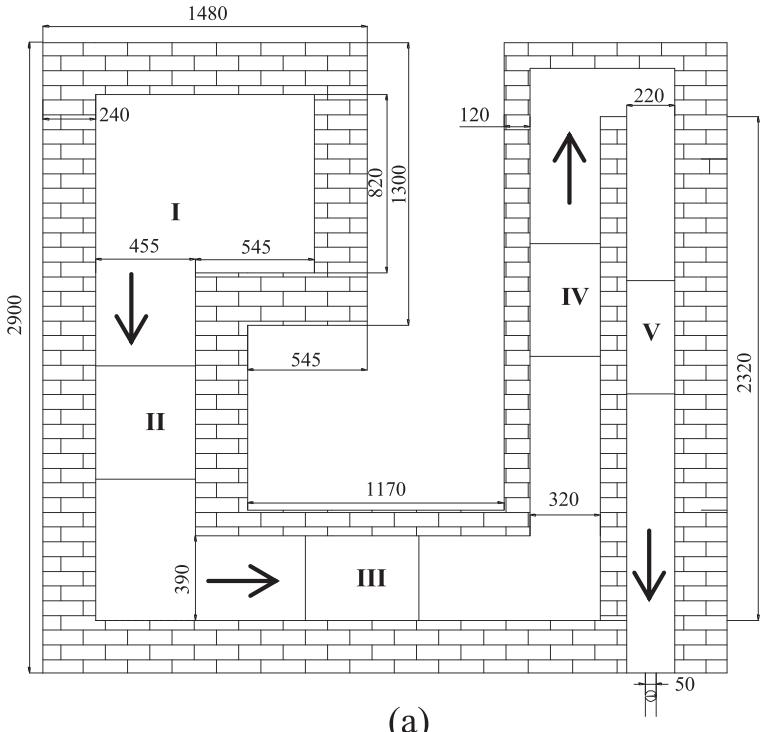

(a)

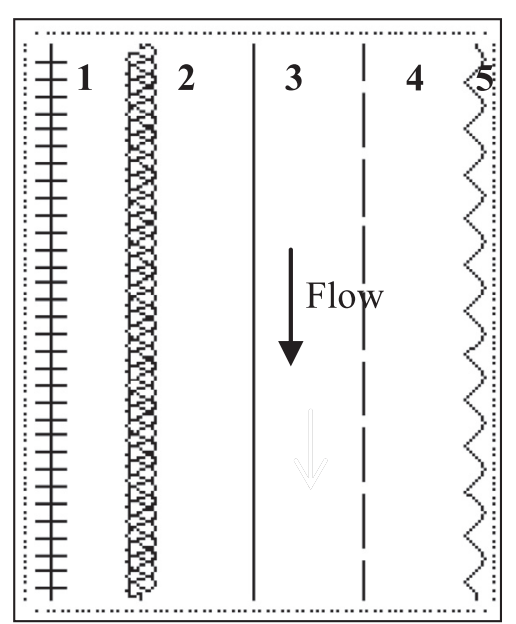

(b)

Fig. 3. (a) Layout of experimental flume, in which flow depth was $0.5 \mathrm{~m}$; (b) Layout of the materials in the frame: 1- bamboo, 2- plastic plane with lumpy surfaces, 3- PP plane (one rough surface and one cement mortar surface), 4- geotextile cloth, 5- woven net. 


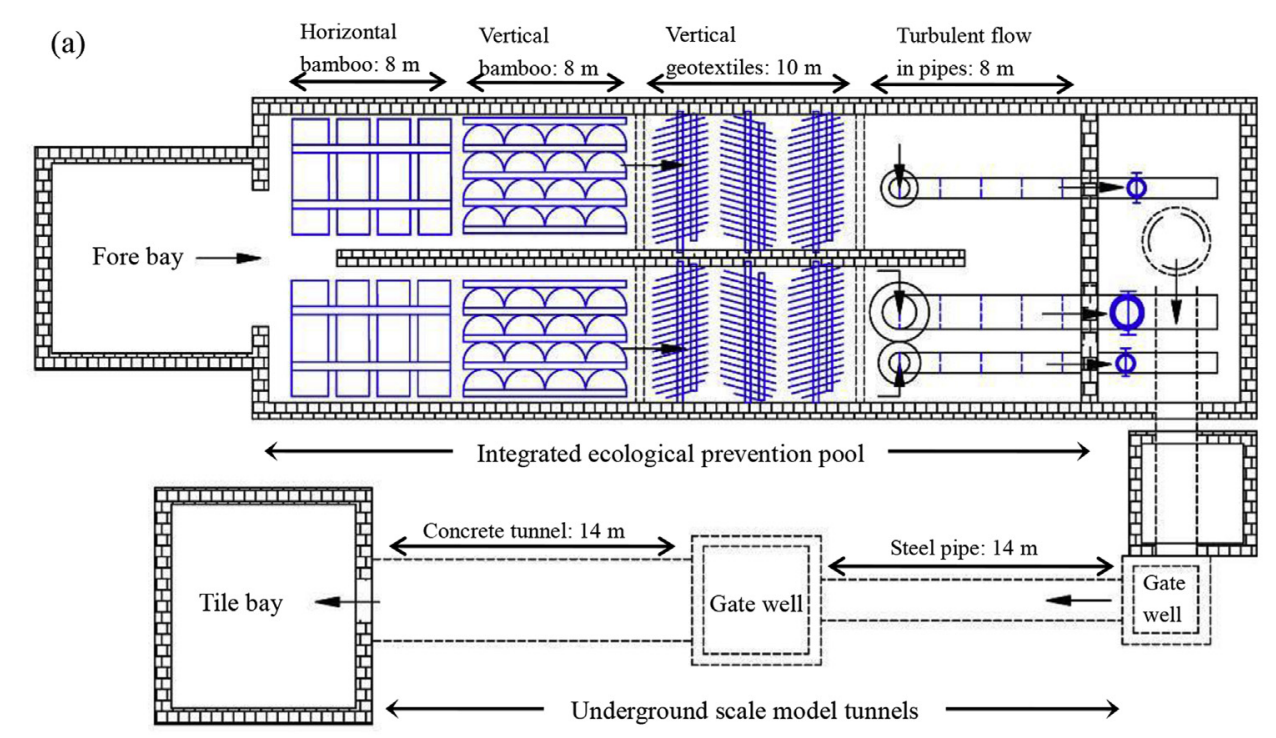

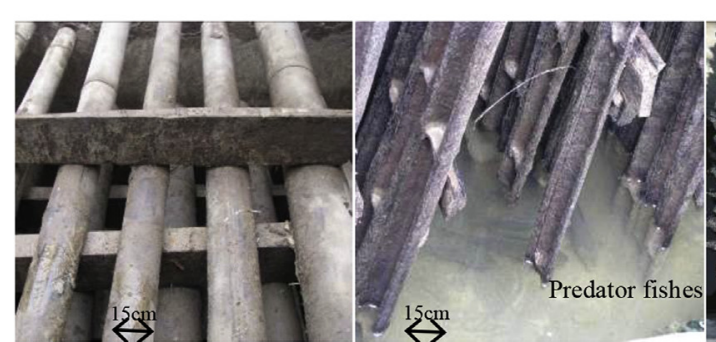

(b) (c)

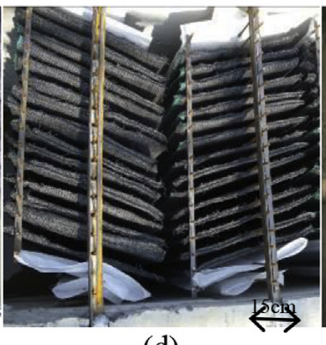

(d)

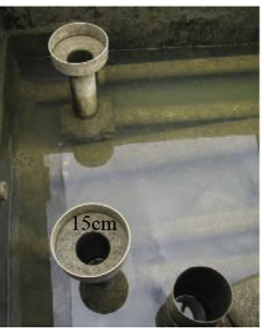

(e)

(f)

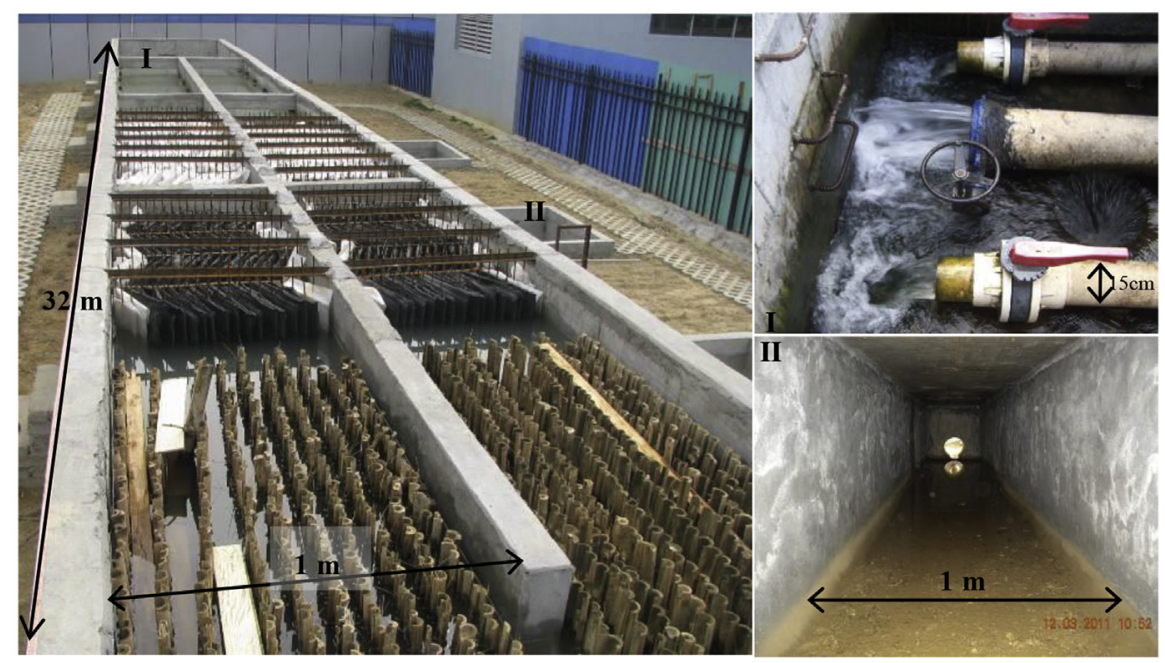

Fig. 4. The layout of the experimental system: (a) Demonstration of the integrated ecological prevention pool; (b) Horizontal bamboo rafts; (c) Vertical bamboo rafts and predator fishes of the golden mussel; (d) Vertical geotextile cloth frames; (e) Inlet of turbulent flow pipes; (f) I-outlet of turbulent flow pipes, II-concrete scale model tunnel.

frames (10 m long), and a section of high frequency turbulent flows created in the three pipes embedded with hole-plates (as described in 2.2.1) (as shown in Fig. 4a). In the sections of bamboo rafts (Fig. 4b and c), the average velocity was kept between 0.4 and $0.6 \mathrm{~m} / \mathrm{s}$ and the average water depth was about $1.5 \mathrm{~m}$. The predators Carassius auratus and Channa argus, were cultured to restrain the attachment density of the golden mussel in these sections. In the section of geotextile cloth frames (Fig. 4d), the average velocity was between 0.2 and $0.3 \mathrm{~m} / \mathrm{s}$ and the average water depth was about $1.5 \mathrm{~m}$. In the section of high frequency turbulent flows, the inlets of the pipes were close to the water surface of the pool (Fig. 4e) and the outlets of the pipes were at the pool bottom and discharged water freely out from the pool (Fig. 4f). Therefore, the $1.5 \mathrm{~m}$ waterhead drove the water flowing through the pipes embedded with hole-plates and created the high frequency turbulent flows in the pipes. Afterwards, the water discharged from the pipes flowed down to the underground scale model tunnels (Fig. 4 a: the $14 \mathrm{~m}$ long steel pipe and $14 \mathrm{~m}$ long concrete tunnel). 
Water samples were taken from the fore bay (Fig. 4a) and the end of the prevention pool to assess the variation of densities of living veligers during the experiment. At the end of the eight-month experiment, the pumps were switched off and water was drained out from the whole experiment system. The attachment densities of the golden mussel on the walls of the prevention pool and the underground scale model tunnels and the attachment materials were measured by dividing the numbers of the attached mussels by the attachment areas. Take the density on the vertical bamboo rafts as an example, each bamboo raft was divided into 3 parts: the surface part (water depth $H=0-0.5 \mathrm{~m})$, the middle part $(H=0.5-1.0 \mathrm{~m})$, and the bottom part $(H=1.0-1.5 \mathrm{~m})$, the mussels attached on each part were numbered and measured with shell length. Then the attachment density of each part was obtained by dividing the total number of attached mussels by the area of each part. The efficiency of the integrated ecological prevention pool was assessed by the variation of the attachment densities of the pool walls and the model tunnel walls.

\section{Results and discussion}

\subsection{Golden mussel veligers}

It is fundamental to know the dynamic distribution of this invading species to have access to basic information to predict distribution/dispersion pattern (Darrigran et al., 2009). After our long-term frequent water samplings and observations, the golden mussel veligers were finally found in the water samples of both the East and Xizhijiang rivers. By comparing these veligers with the features of golden mussel veligers reported in South America (Dos Santos, 2005; Cataldo, 2005), it was confirmed that golden mussel veligers were released into the water and experienced about a one-month period of varying plankton stages in water. Fig. 5 shows the three different veliger stages: D-shape veligers, pediveligers, and plantigrade veligers. This is the first time that golden mussel veligers were found living in water in China, which is essential for the further study of preventing the golden mussel invasion.

Our observations showed that the plankton veligers invade with water flow to all sections of the water transfer tunnels, resulting in the serious biofouling. The densities of the golden mussel veligers varied from several hundred up to more than
10,000 ind. $/ \mathrm{m}^{3}$ in different months, and peaked from May to August, during which the most intensive invasion occurred. This agrees with Darrigran et al. (2007), prevention of plankton veligers from invading in the industries of the facility or tunnels during this period is considered to be the most effective control strategy.

The living statuses of the veligers were observed after they were treated with high frequency turbulence under different action time, as shown in Fig 6 (a) and (b). Either the tissues of the veligers were broken and released out from the shells or the shells were damaged due to the high frequency turbulence. As shown in Fig. 6c, the rate of the veligers killed by the turbulence increased with the action time of the turbulence. More than $80 \%$ of the veligers were killed when the action time was over $5 \mathrm{~min}$, and all of the veligers were killed when the action time was over $10 \mathrm{~min}$. The veligers of zebra mussels were also observed being killed in the turbulent flow created by an aerating pump when the eddy scale was comparable with the veliger sizes (Rehmann et al., 2003). Therefore, such high frequency turbulence $(>30 \mathrm{~Hz})$ can be used to control the invasion of the golden mussel and zebra mussel. However, the energy consumption requirements of creating this turbulence may restrict its application in practice.

\subsection{Attachment characteristics of the golden mussel}

Observation of the attachment activities of the veligers indicated that when they developed into plantigrade veligers, they began to attach onto various materials. They experienced an unstable veliger-attachment stage and then a stable musselattachment stage with their byssuses, successively. The attachment of veligers with lengths of $200-400 \mu \mathrm{m}$ was unstable. These veligers usually moved from their original attachment places and back to water flow to find suitable habitat. When the veligers grew longer than $450 \mu \mathrm{m}$, they produced byssuses and used them to attach onto materials firmly. Once attached, these veligers hardly moved and developed into mussels in their current location. Fig. 7 shows the characters of the stable mussel-attachment.

As shown in Fig. 7a, the attachment force is positively correlated to the mussel length. Normally, longer mussels produce larger and stronger byssuses (Xu et al., 2012). The inflated suckers of the byssuses attached firmly on materials

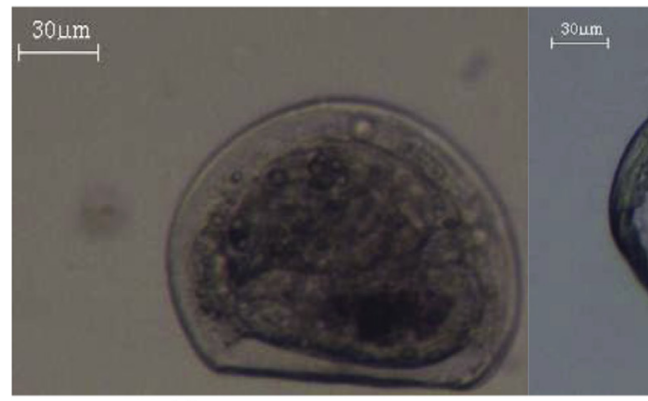

(a)

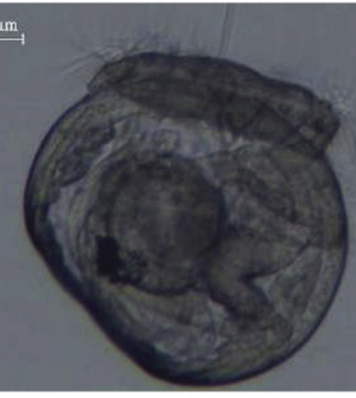

(b)

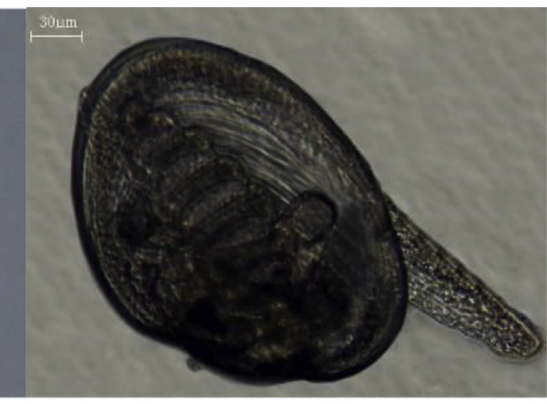

(c)

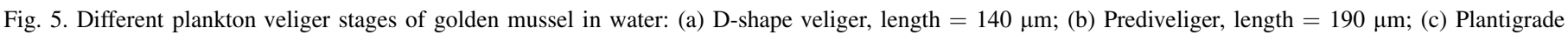
veliger, length $=320 \mu \mathrm{m}$. 


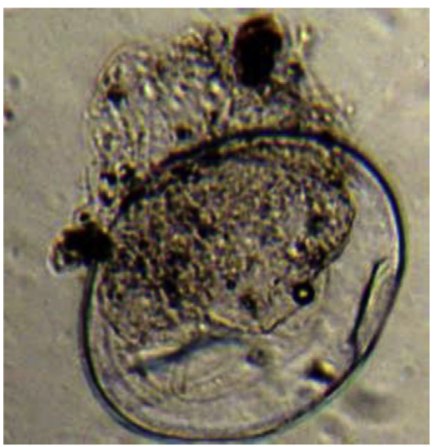

(a)

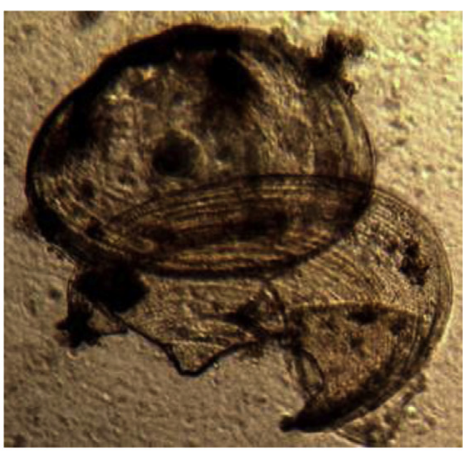

(b)

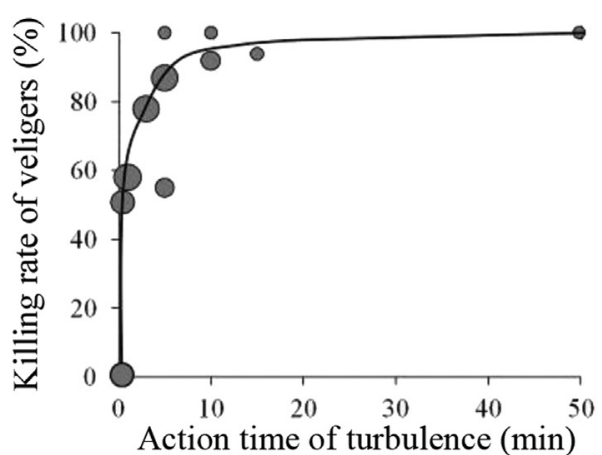

(c)

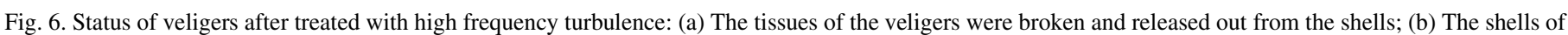

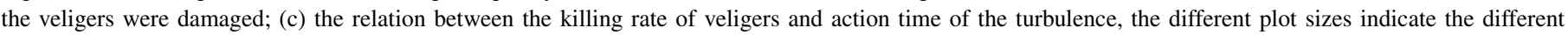
densities of the veligers.

and were difficult to remove (Fig. 7b). As shown in Fig. 7c, the average flow velocity that caused the attached mussels to dislodge from a material (called "falling velocity") shows a linear relationship with the product of the number and average diameter of the byssuses that were used for attaching. All of the attached mussels fell off when the flow velocity reached $2.2 \mathrm{~m} / \mathrm{s}$. This agrees with Ye et al. (2011), which indicated that in the water transfer tunnels of ERWSP the attachment density of the golden mussel was very low at the sections with flow velocity higher than $2.0 \mathrm{~m} / \mathrm{s}$.

Fig. 8 shows the attachment densities of the golden mussel on different materials under different attachment time. After one day, a few mussels were found attaching onto geotextile cloth, PP plane, and woven net. After one week, the attachment densities on all of the materials increased. To be specific, the density on the geotextile cloth reached its maximum. After two weeks, the attachment density on most of the materials increased. Especially on the bamboo the density increased dramatically and became much higher than that on the other materials. However, the density on geotextile decreased significantly compared to its density at one week. After four weeks, except for PP plane with cement mortar surface, the densities on the materials seldom changed compared to their density at two weeks. Therefore, a time of two weeks is considered to be the threshold for the golden mussel's stable attachment.
Nevertheless, the golden mussel attachment shows preference to materials. Bamboo was the most favoured habitat for the mussels in the stable attachment stage, while geotextile cloth was the most popular material for those in the unstable attachment stage. Therefore, using geotextile cloth is recommended to absorb the golden mussel individuals in the unstable attachment stage. The geotextile cloth should be replaced every one week before the attached mussels releasing themselves off from the material. By this way the attached mussels are taken out from the water flow. Bamboo is recommended to be used as a suitable habitat material to attract the individuals in the stable attachment stage. It is important that the bamboo habitat should be replaced before the attached mussels reach sexual maturity (mussel length $\geq 6-8 \mathrm{~mm}$ ). With addition of these two types of materials, less mussels invade into water transfer tunnels. However, the plastic plane with lumpy surfaces, which releases toxicity, is the least welcomed attachment material and supposed to be used to avoid the golden mussel attachment in certain circumstance.

\subsection{Integrated ecological prevention}

As recommended in 3.2, bamboo rafts were used as habitat materials for the golden mussel's stable attachment and geotextile frames were used to absorb the individuals that were in the stage of unstable attachment and escaped from the bamboo

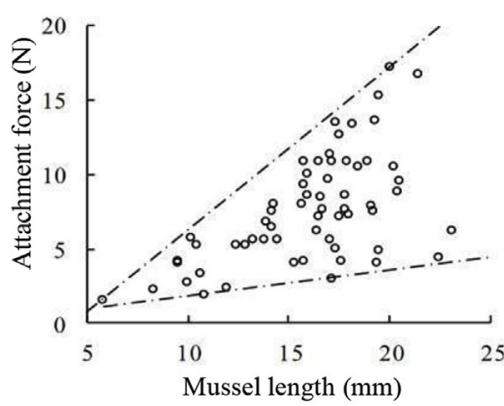

(a)

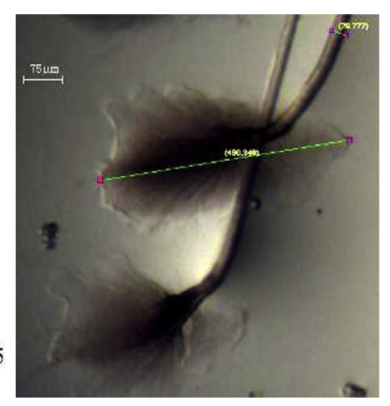

(b)

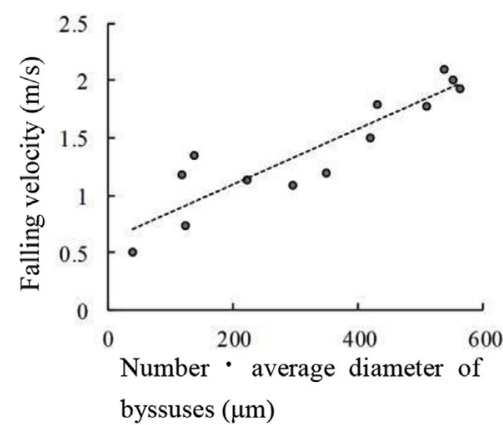

(c)

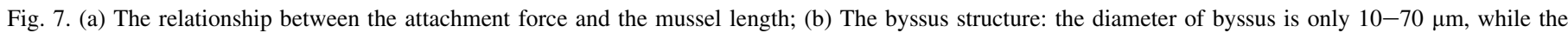
diameter of sucker is $>1000 \mu \mathrm{m}$; (c) The relationship between falling velocity and the product of the number and average diameter of the byssuses. 


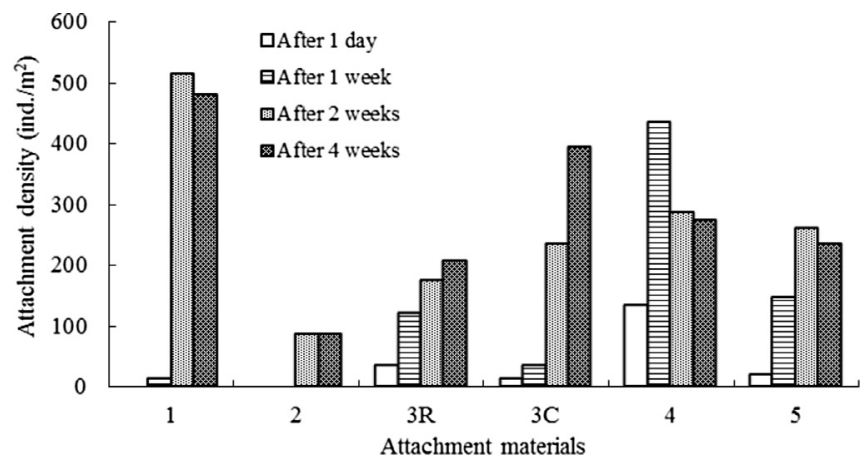

Fig. 8. The attachment densities of the golden mussel on different materials after different attachment times. Note: 1-bamboo, 2-plastic plane with lumpy surfaces, 3R-PP plane with rough surface, 3C-PP plane cement mortar surface, 4- geotextile cloth, 5- woven net.

rafts in the integrated ecological prevention pool. During the eight-month experiment, Carassius auratus and Channa argus played important roles in restraining both attachment density and shell length of the golden mussel in the prevention pool. The total density and biomass of $C$. auratus and $C$. argus in the prevention pool was 2 and 7 times, respectively, higher than that of the control, in which the fishes was cultivated in the same water, however, with no attachment materials attracting the golden mussel's attachment (Xu, 2012). Most of the golden mussel individuals on the bamboo rafts were shorter than their sexually mature shell length. The pipes in the end section of the prevention pool created high frequency turbulent flows and worked as the final guarantee to reduce the living veligers.

The attachment densities on the bamboo rafts and geotextile frames at different water depths and distances from the fore bay were compared in Fig. 9. Firstly, the orientation of the attachment materials affected the attachment densities. The attachment densities on the horizontal bamboo were much lower than the attachment densities on the vertical bamboo rafts and the vertical geotextile frames, because the horizontal bamboo rafts were more prone to precipitation of silt and clay. Clay and silt precipitates interfere with filter-feeding, breathing, and attachment of the golden mussel (Morton, 1977; Darrigran et al., 2011). In the water transfer tunnels, it is also found that the walls with more clay and silt precipitates have lower attachment density of the golden mussel than those with less clay and silt precipitates (Ye et al., 2011).

Furthermore, for the sections with vertical bamboo rafts and geotextile frames, the attachment densities decreased as the distance from the fore bay increased; and it reduced to nearly zero ind $/ \mathrm{m}^{2}$ at the end of these sections, which indicated that nearly all mussels were prevented in the sections with attachment materials. Nevertheless, the attachment densities at different water depths were also different $(P$-value indicates the significance of the difference between the densities at different water depths; when $P$-value $<0.05$, the densities are significantly different; when $P$-value $>0.05$, the densities are not significantly different. $P$-value $(H=0-0.5 \mathrm{~m}, H=1-1.5 \mathrm{~m})=0.00012,<0.05 ; P$-value $(H=0-0.5 \mathrm{~m}, H=0.5-1 \mathrm{~m})=0.00113,<0.05$. Therefore, the density at water depth $H=0-0.5 \mathrm{~m}$ is significantly different from those at $H=1-1.5 \mathrm{~m}$ and $H=0.5-1 \mathrm{~m})$. The densities were mostly the highest at the bottom $(H=1-1.5 \mathrm{~m})$, followed by those at the middle $(H=0.5-1 \mathrm{~m})$, and were the lowest at the surface $(H=0-0.5 \mathrm{~m})$. This may be due to the photopathy and benthic characteristics of the golden mussel (Xu et al., 2009). The settling characteristic of the veligers also results in more veligers present in the deeper water (Xu et al., 2013).

Fig. 10a shows the monthly average density and reduction rate of living veligers at the fore bay and the end of the prevention pool during the experiment period. The density of living veligers decreased significantly after the water passed through the pool ( $p$-value between the average density of living veligers at the fore bay and the end of the prevention pool is much less than 0.05). The reduction rate of living veligers was over $80 \%$. Very few living veligers, most of which were in their D-shape and prediveliger stages and not ready for stable attachment, entered into the scale model tunnels, but did not cause biofouling (as shown in Fig. 10b).

Fig. 10b shows the attachment density of the golden mussel on the walls from the fore bay to the tile bay after eight months' experiment. The attachment density decreased dramatically from the wall of the fore bay to the wall of the

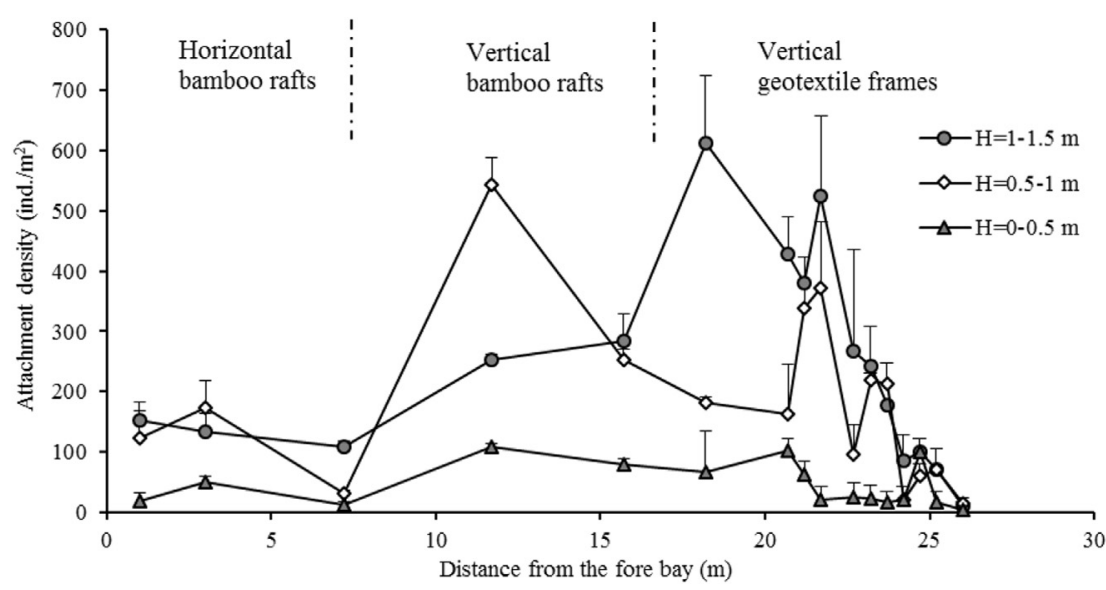

Fig. 9. Attachment densities of the golden mussel on the different materials at different water depths and distances from the fore bay. 


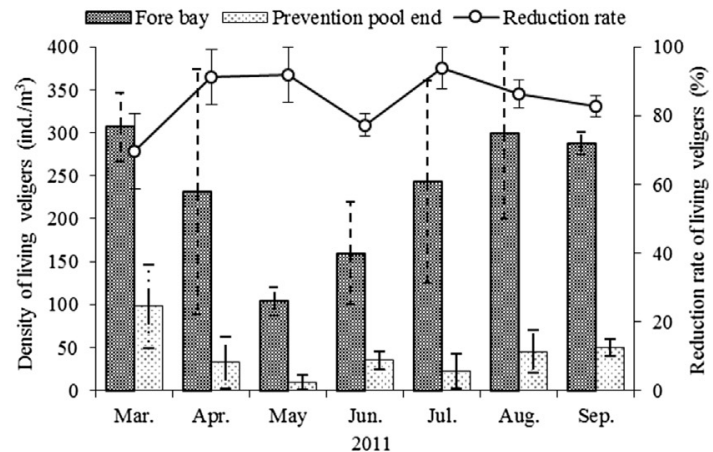

(a)

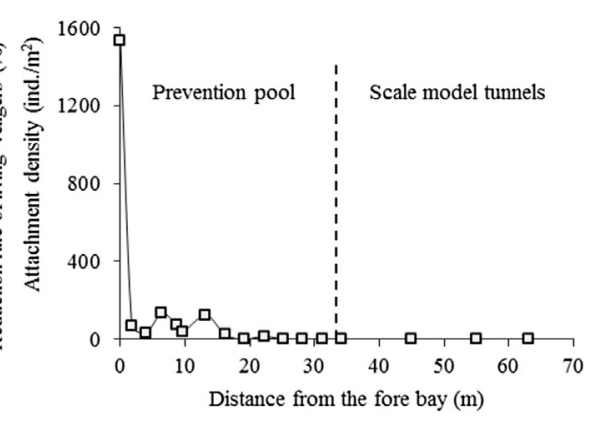

(b)

Fig. 10. (a) Density and reduction rate of living veligers at the fore bay and the prevention pool end during the experiment period ( $P$-value (density of living veligers at fore bay, density of living veligers at prevention pool end) $=0.000045,<0.05$ ); (b) Attachment density of the golden mussel at walls from the fore bay to the tile bay.

section of the prevention pool with bamboo rafts. Then it reduced to zero ind. $/ \mathrm{m}^{2}$ on the wall of the section of geotextile frames of the pool. No mussels were found on the wall of the scale model tunnels. It is thought that when water flowed into the section of bamboo rafts, the veligers that were ready for stable attachment were attracted to attach on the bamboo. Then water flowed into the section with geotextile frames; the veligers that were in an unstable stage of their lifecycle were absorbed on the geotextile frames. Therefore, most of the veligers were stopped in the prevention pool, and the invasion in the tunnels was controlled.

Fig. 11 compared the attachment of the golden mussel on the gate wells in the tunnels of ERWSP and the scale model tunnels. Without prevention measures, the gate well in the tunnel of ERWSP suffered from the serious golden mussel biofouling (Fig. 11a). Conversely, in the scale model tunnels there was no golden mussel attached (Fig. 11b), because the integrated ecological prevention pool successfully controlled the golden mussel invasion.

The integrated ecological prevention pool has been tested in the tunnel section of the Xizhijiang Pump Station in 2013. The pool was installed at the Xizhijiang River intake, where the Xizhijiang water was pumped to the pool before entering the tunnel. Fig. 12 compares the attachment density of mussels on the tunnel wall before (2012) and after (2013) the application of the integrated prevention. Fig. 12 (a), for the tunnel section from the East River intake to the upstream of the Xizhijiang intake, the attachment densities of 2012 and 2013 seldom varied since no prevention measure was applied at the East River intake. However, for the tunnel section from the Xizhijiang intake to its downstream section, due to the application of the prevention pool, the attachment density decreased as much as $80 \%$, e.g. from 20,800 ind. $/ \mathrm{m}^{2}$ in 2012 to 4933 ind. $/ \mathrm{m}^{2}$ in 2013. Fig. 12 (b) shows the tunnel section at the Xizhijiang Pump Station attached by enormous mussels before the application of the integrated prevention. Fig. 12 (c) shows the same section, where very few mussels attached after the prevention application in 2013.

\section{Conclusions}

The golden mussel underwent planktonic veliger stages in water. The movement ability of both the veligers and mussels was poor. Their invasion in water transfer tunnels was achieved because planktonic veligers were transported by water flow. Planktonic veligers were killed in high frequency turbulence when the eddy scale was comparable with the veliger size. The killing rate of veligers was positively correlated with the action time of the turbulence. After the veligers entered a tunnel, they begin to attach and grew into mussels on the tunnel walls. After attachment, they developed from the unstable veliger-attachment stage to the stable mussel-

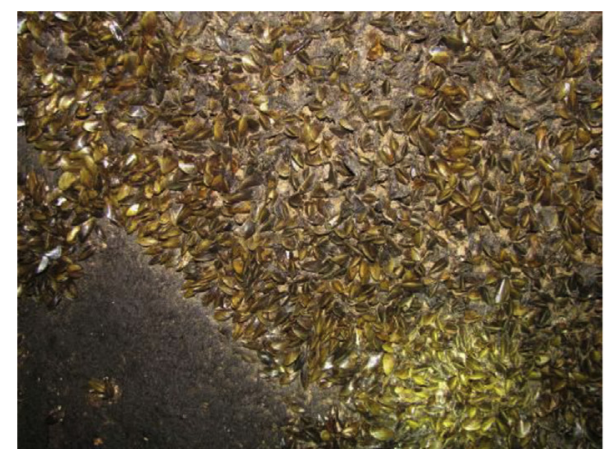

(a)

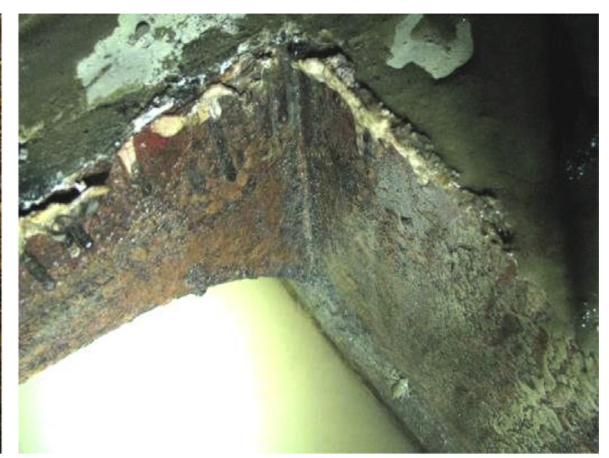

(b)

Fig. 11. Attachment of the golden mussel in 2011: (a) The wall of gate well in the tunnels of ERWSP; (b) The wall of gate well in the scale model tunnels. 


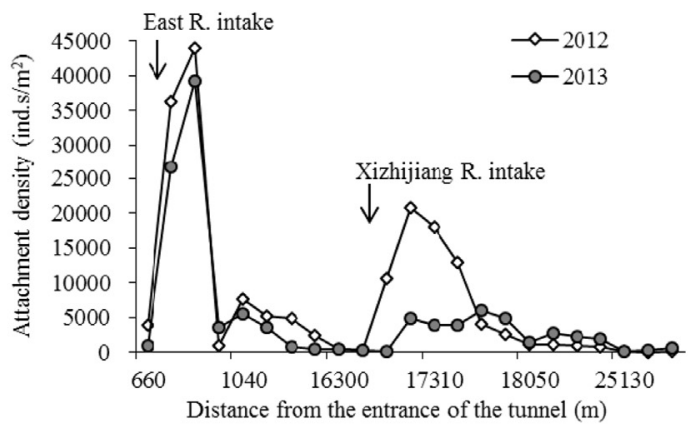

(a) Attachment density along distance from the tunnel entrance

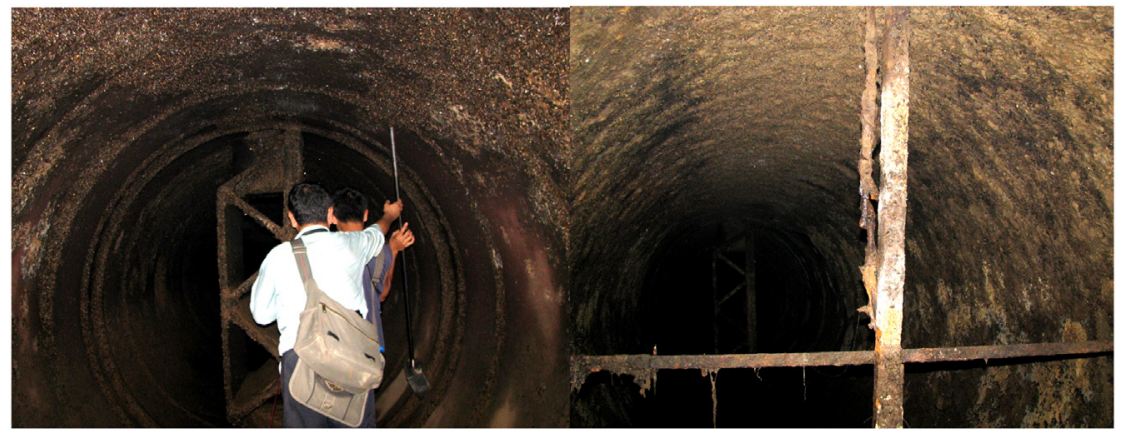

(b) Attachment before the integrated prevention

(c) Attachment after the integrated prevention

Fig. 12. Comparison of golden mussels' attachment on the tunnel wall of ERWSP before and after the integrated prevention.

attachment stage with their byssuses. They preferred geotextile cloth during the unstable attachment stage and bamboo material during the stable attachment stage. When the golden mussel attached stably and firmly on materials, they could withstand the flushing of water flow. Their attachment force was positive to their mussel length. The average flow velocity that caused the golden mussel dislodging from materials showed a linear relation with the product of the number and average diameter of the byssuses used for attaching.

The integrated prevention pool was designed and constructed to prevent the golden mussel veligers from entering into tunnels by attracting mussels to attach stably onto bamboo and absorbing veligers to attach on geotextile cloth. High frequency turbulence was also used as a final guarantee at the end of the prevention pool to reduce the amount of living veligers that may enter into tunnels. An eight month experiment using this prevention pool indicates that these methods successfully controlled the golden mussel invasion and biofouling in the model tunnels. The sections of attachment materials were very effective in preventing the veligers from invading in the scale model tunnels. The mussel density on the attachment materials decreased sharply as the distance from the pool entrance increased and reduced to nearly zero at the end of pool. The predator fishes restrained the densities and shell lengths of the stably attached mussels. The high frequency turbulence was effective in killing veligers that escaped from the attachment sections. No golden mussel attached in the scale model tunnels. The application of the integrated prevention pool at the Xizhijiang intake also indicated that the prevention pool has effectively reduced the attachment density of golden mussels in the tunnel section. Therefore, the integrated prevention pool is recommended as a successful measure of controlling the golden mussel invasion and biofouling in the water transfer tunnels.

\section{Acknowledgements}

This study was supported by the Natural science foundation of China (51409146; 51479091), Ministry of Water Resources of China (200901078), and International Science \& Technology Cooperation Program of China (2011DFA20820). The authors would like to thank the reviewers and editors for their comments that helped improve the manuscript.

\section{References}

Belz, C., Darrigran, G., Netto, O.M., Junior, P.R., 2012. Analysis of four dispersion vectors in inland waters: the case of the invading Bivalves in South America. J. Shellfies Res. 31 (3), 777-784.

Boltovskoy, D., Correa, N., Cataldo, D., Sylvester, F., 2006. Dispersion and impact of invasive freshwater bivalves: Limnoperna fortunei in the Río de la Plata watershed and beyond. Biol. Invasions 8, 947-963.

Cataldo, D., Boltovskoy, D., Hermosa, J.L., Canzi, C., 2005. Temperaturedependent larval development rates of Limnoperna fortunei (Mollusca, Bivalvia). J. Molluscan Stud. 71, 41-46.

Darrigran, G., Damborenea, C., 2006. Bio-invasión del mejillón dorado en el continentea mericano. Buenos Aires, Argentina (in Spanish).

Darrigran, G., 2002. Potential impact of filter-feeding invaders on temperate inland fresh water environments. Biol. Invasions 4, 145-156.

Darrigran, G., Ezcurra, de D.I., 2000. Invasion of Limnoperna fortunei (Dunker, 1857) (Bivalvia: Mytilidae) in america. Nautilus 2, 69-74.

Darrigran, G., 2010. Summary of the distribution and impact of the golden mussel in argentina and neighboring countries. In: Claudi, Renata, 
Mackie, Gerald (Eds.), Practical Guide for the Monitoring and Control of Aquatic Invasive Molluscs in Freshwater Systems. Taylor and Francis Group, LLC.

Darrigran, G., Boeger, W., Maroñas, M., 2009. Evaluation of sampling and analysis techniques for early detection of Limnoperna fortunei (Mytilidae) in limit areas of its distribution. Braz. J. Biol. 69 (3), 979-980.

Darrigran, G., Damborenea, C., 2011. Ecosystem engineering impacts of Limnoperna fortunei in South America. Zool. Sci. 28, 1-7.

Darrigran, G., Damborenea, M.C., 2005. A bioinvasion history in South America. Limnoperna fortunei (Dunker, 1857), the golden mussel. Am. Malacol. Bull. 20, 105-112.

Darrigran, G., Damborenea, C., Drago, E., Ezcurra de Drago, I., Paira, A., Archuby, F., 2012. Invasion process of Limnoperna fortunei (Bivalvia, Mytilidae): the case of Uruguay River and emissaries of the Esteros del Iberá Wetland (Argentina). Zoologia 29 (6), 531-539.

Darrigran, G., Damborenea, C., Drago, E., Ezcurra de Drago, I., Paira, A., 2011. Environmental factors restrict the invasion process of Limnoperna fortunei (Mytilidae) in the Neotropical Region: a case study from the Andean tributaries. Ann. Limnol. 47 (3), 221-229.

Darrigran, G., Damborenea, C., Greco, N., 2007. Freshwater invasive bivalves in man-made environments: a case study of larvae biology of Limnoperna fortunei in a hydroelectric power plant in South America. AMBIO 36 (7), 575-579.

Darrigran, G., Penchaszadeh, P., Damborenea, M.C., 1999. The life cycle of Limnoperna fortunei (Dunker 1857) (Bivalvia:Mytilidae) from a neotropical temperate locality. J. Shellfish Res. 18 (2), 361-365.

Dos Santos, C.P., Wurdig, N.L., Mansur, M.C.D., 2005. Fases larvais do mexilhao dourado limnoperna fortunei (Dunker) (Mollusca, Bivalvia, Mytilidae) na bacia do Guaiba, Rio Grande do Sul, Brasil. Rev. Bras. Zool. 22 (3), 702-708.

Dunker, W., 1856. Mytilacea nova collectionis Cumingiana. Proc. Zool. Soc. Lond. 24, 358-366.

Group of Pipeline Study, the Chinese academy of sciences institute of aquatic organisms, 1973. Biology of golden mussel (Limnoperna fortunei). Anim. use Prev. 33-36 (in Chinese with English abstract).

Karatayev, A., Boltovskoy, D., Padilla, D., Burlakova, L., 2007. The invasive bivalves Dreissena polymorpha and Limnoperna fortunei: parallels, contrasts, potential spread and invasion impacts. J. Shellfish Res. 26 (1), 205-213.

Liu, Y.Y., Zhang, W.Z., Wang, Y.X., 1979. China's Economic Animal Annals (Freshwater Molluscs). Science Press, Beijing, China (in Chinese with English abstract).

Luo, F.M., 2006. Studies on Biology and Control Techniques of Limnoperna Fortunei (Dunker) in Water Supply System of Shenzhen City. Master's thesis. Nanchang University, Nanchang (In Chinese with English abstract).

Magara, Y., Matsui, Y., Goto, Y., Yuasa, A., 2001. Invasion of the nonindigenous nuisance mussel, Limnoperna fortunei, into water supply facilities in Japan. J. Water Supply: Res. Technol. AQUA 50, 113-124.

Márcia, D., 2006. The limnological characteristics of aquatic environments which support the golden mussel (Limnoperna fortunei, Dunker, 1857) and the potential of the golden mussel to further spread within the Paraguay
River Basin, Brazil. In: Proceeding: 14th International Conference on Aquatic Invasive Species. Florida, p. 205.

Morton, B.S., 1979. Freshwater fouling bivalves. In: Proceedings of the First International Corbicula Symposium. Texas Christian University, Fort Worth, Texas.

Morton, B., 1977. The population dynamics of Limnoperna fortunei (Dunker 1857) (Bivalva: Mytilacea) in Plover Cove reservoir, Hong Kong. Malacologia 16, 165-182.

Morton, B., 1982. The reproductive cycle in Limnoperna fortunei (Dunker 1857) (Bivalvia: Mytilidae) fouling Hong Kong's raw water supply system. Oceanol. limnol. 13, 319-324.

Penchaszadeh, P.E., Darrigran, G., Angulo, C., Averbuj, A., Broegger, M., Dogliotti, A., Pirez, N., 2000. Predation on the invasive freshwater mussel Limnoperna fortunei (Dunker, 1857) (Mytilidae) by the fish Leporinus obtusidns Valenciennes, 1846 (Anostomidae) in the Río de la Plata, Argentina. J. Shellfish Res. 19, 229-231.

Pereyra, P.J., Bulus Rossini, G., Darrigran, G., 2011. Toxicity of three commercial tannins to the nuisance invasive species Limnoperna fortunei (Dunker, 1857): implications for control. Fresenius Environ. Bull. 20 (6), $1432-1437$.

Pereyra, P.J., Bulus Rossini, G., Darrigran, G., 2012. Toxicity of Neem's oil, a potential biocide against the invasive mussel Limnoperna fortunei (Dunker 1857). An. Acad. Bras. Ciências 84 (4), 1065-1071.

Rehmann, C.R., Stoeckel, J.A., Schneider, D.W., 2003. Effect of turbulence on the mortality of zebra mussel veligers. Can. J. Zool. 81, 1063-1069.

Ricciardi, A., 1998. Global range expansion of the asian mussel Limnoperna fortunei (Mytilidae): another fouling threat to freshwater systems. Biofouling 13 (2), 97-106.

Simberloff, D., 2001. Eradication of island invasives: practical actions and results achieved. Trends Ecol. Evol. 16, 273-274.

Xu, M.Z., 2012. Experimental Study of Macroinvertebrate Limnoperna Fortunei Invasion and Prevention in Water Transfer Tunnels. Doctor's thesis. Tsinghua University, Beijing (in Chinese with English abstract).

Xu, M.Z., 2013. Experimental study of bio-fouling control of Limnoperna fortunei in water transfer tunnels. In: Proceedings of 2013 IAHR Congress (C) 2013. Tsinghua University Press, Beijing.

Xu, M.Z., Cao, X.W., Wang, Z.Y., Wang, X.Z., 2012. Attachment character of golden mussels (Limnoperna fortunei) invaded in water transport project. J. Tsinghua Univ. Sci. Tech. 52 (2), 170-176 (in Chinese with English abstract).

Xu, M.Z., Wang, Z.Y., Duan, X.H., Zhuang, M.Q., de Souza, F.T., 2009. Ecological measures of controlling invasion of golden mussel (Limnoperna fortunei) in water transfer systems. In: The 33rd IAHR Congress: Water Engineering for a Sustainable Environment. International Association of Hydraulic Engineering and Researchm, pp. 1609-1616.

Xu, M.Z., Wang, Z.Y., Wang, X.Z., Liu, W., 2013. Golden mussel invasion in water transfer tunnels and hydraulic prevention. Shuili Xuebao 44 (7), 856-872 (in Chinese with English abstract).

Ye, B.M., Cao, X.W., Xu, M.Z., Wang, Z.Y., Lin, C.C., 2011. Study of Limnoperna fortunei invasion in water transport project. Water Wastewater Eng. 37, 99-102 (in Chinese with English abstract). 